\title{
Digital messaging to support control for type 2 diabetes (StAR2D): a multicentre randomised controlled trial
}

\author{
A. Farmer ${ }^{1 *+} \mathbb{D}$, K. Bobrow $^{2+}$, N. Leon ${ }^{3}$, N. Williams ${ }^{1}$, E. Phiri ${ }^{4}$, H. Namadingo ${ }^{4}$, S. Cooper ${ }^{5}$, J. Prince ${ }^{6}$, A. Crampin ${ }^{4}$, \\ D. Besada ${ }^{3}$, E. Daviaud ${ }^{3}$, L-M Yu ${ }^{1}$, J. N'goma ${ }^{7}$, D. Springer ${ }^{8}$, B. Pauly ${ }^{9}$, L. Tarassenko ${ }^{6}$, S. Norris ${ }^{10}$, M. Nyirenda ${ }^{4}$ and \\ N. Levitt ${ }^{2}$
}

\begin{abstract}
Background: Failure to take medicines for diabetes as prescribed contributes to poor outcomes from the condition. Mobile phones are ubiquitous and short message service (SMS) texts have shown promise as a low-cost intervention. We tested the effectiveness of SMS-text messaging in improving outcomes in adults with type 2 diabetes.

Methods: StAR2D was a 12-month two-arm randomised trial of SMS-text messaging and usual care in Cape Town, South Africa and Lilongwe, Malawi. Messages used behaviour change theory and were developed with patients and staff. The intervention group received four messages each week. The primary outcome was change in HbA1c. Secondary outcomes were the proportion of patients who collected $>80 \%$ medication and changes in systolic blood pressure, lipids, cardiovascular risk, and the proportion of the participants reaching treatment goals.

Results: The trial took place between 1 October, 2016 and 1 October 2018, 1186 participants were randomised to intervention (593) and control (593) groups. 91\% of participants completed follow-up. There was a reduction in $\mathrm{HbA1c}(\mathrm{DCCT})$ in both groups but not in mean change ( $95 \% \mathrm{Cl})$ between groups $(-0.08 \%(-0.31$ to 0.16$)$ (IFCC $0.82 \mathrm{mmol} / \mathrm{mol}$ ( -3.44 to 1.79 ). There was a small but not significant increase in the proportions of participants likely to have collected $80 \%$ or more of medication (Relative risk 1.11 ( 0.84 to $1.47 ; P=0.47$ ). There was a significant difference between groups in change in systolic blood pressure from baseline of $3.46 \mathrm{mmHg}$ (1.48 to $5.44, P=$ 0.001) in favour of the intervention group. The between group difference in change in 10-year risk of coronary heart disease was $-0.71 \%(-1.46$ to $0.04, P=0.064)$. The proportion of participants meeting treatment goals in the intervention group was $36.0 \%$ and in the control group 26.8\% (Relative risk $1.36(1.13$ to $1.63, P=0.001)$. Participants reported many challenges to adherence despite finding messages acceptable and useful.
\end{abstract}

\footnotetext{
* Correspondence: andrew.farmer@phc.ox.ac.uk

A Farmer and K, Bobrow are equal first author.

${ }^{+}$A. Farmer and K. Bobrow contributed equally to this work.

${ }^{1}$ Nuffield Department of Primary Care Health Sciences, University of Oxford, Oxford, UK

Full list of author information is available at the end of the article
}

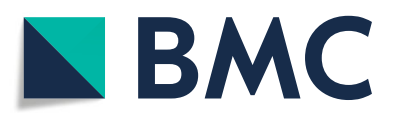

(c) The Author(s). 2021, corrected publication 2022. Open Access This article is licensed under a Creative Commons Attribution 4.0 International License, which permits use, sharing, adaptation, distribution and reproduction in any medium or format, as long as you give appropriate credit to the original author(s) and the source, provide a link to the Creative Commons licence, and indicate if changes were made. The images or other third party material in this article are included in the article's Creative Commons licence, unless indicated otherwise in a credit line to the material. If material is not included in the article's Creative Commons licence and your intended use is not permitted by statutory regulation or exceeds the permitted use, you will need to obtain permission directly from the copyright holder. To view a copy of this licence, visit http://creativecommons.org/ licenses/by/4.0/. The Creative Commons Public Domain Dedication waiver (http://creativecommons.org/publicdomain/zero/1. 0/) applies to the data made available in this article, unless otherwise stated in a credit line to the data. 
Conclusions: Whilst SMS text messages do not lead to improved glycaemia in these low-resource settings there appeared to be an impact on blood pressure and achievement of treatment goals but the mechanisms for this are unclear. Text messages alone, may be unsuccessful unless accompanied by health system strengthening and other forms of self-management support for type 2 diabetes.

Trial registration: Trial registration: ISRCTN, ISRCTN70768808. Registered 1 July 2015, http://www.isrctn.com/I ISRC TN70768808.

Keywords: Digital health, Adherence, Type 2 diabetes, Randomised trial, Sub-Saharan Africa, SMS text-messages

\section{Background}

The increasing burden of type 2 diabetes and its associated poor health outcomes disproportionately affects populations in low- and middle-income countries (LMIC) [1-3]. Effective management for people with diabetes requires a system of care to be in place that includes availability of various health care providers, access to treatments for blood glucose control as well as control of blood pressure and cholesterol levels, support for self-management, and strategies to detect and manage known complications from this progressive chronic condition [4].

The difficulties for patients in not collecting or taking medications have been extensively described and include a range of concerns and anxieties, lack of social support, limited health literacy, and negative interactions with the health care systems and lack of support for self-management $[5,6]$. However, even with well- systems of care in place, failure to take medicine as prescribed or to follow other recommendations around diet and lifestyle, often referred to as nonadherence, can result in a failure to deliver the benefits of effective medical treatments into better outcomes for individual patients [6,7].

Some but not all, interventions delivered by short message service (SMS) text messaging have been effective in increasing adherence to treatment and improving health outcomes for a range of chronic health conditions [8-10]. A systematic review suggests significant benefits of SMS text messaging for medication support in type 2 diabetes, but identified substantial heterogeneity in study length, study design with respect to the intervention and the comparator, and in content of the intervention. Studies included both high- and low-income settings, however there are few controlled studies from sub-Saharan Africa [11], and no studies comparing interventions across different health systems [12]. Controlled studies of longer duration, the use of structured message development, and carried out in sub-Saharan Africa are needed to understand and guide the use of digital health interventions.

Following formative work to develop messages and refine message delivery, we tested the effectiveness of sending SMS text messages in improving health outcomes and medication adherence in patients with type 2 diabetes compared to usual care in two low- and middle-income countries, Malawi and South Africa. We also carried out a process evaluation using qualitative research methods alongside the trial to investigate participant responses and acceptability, and we examined the cost of the intervention through a formal cost analysis.

\section{Methods \\ Study design and participants}

The SMS-Text Adherence Support for Type 2 Diabetes (StAR2D) trial was a 12-month, two parallel-arm, individually randomised controlled trial done in two urban sites serving patients living in middle- and low-income settings in Southern Africa: Cape Town, South Africa, and Lilongwe, Malawi. In Cape Town, recruitment was from a large primary care clinic serving two low-income communities to the north of the city. In Lilongwe, where many of the population live in low-income informal settlements, recruitment was from a hospital-based outpatient clinic. Despite the difference in gross domestic product between South Africa (6374 USD) and Malawi (371 USD), in both settings, there is an aspiration for patients to receive health care free of charge alongside supply of a limited range of essential medicines at no cost to patients. These medications include those to reduce blood glucose and blood pressure. In both sites group diabetes education sessions are provided whilst attending clinics.

\section{Randomisation and masking}

We used a remote Web-based randomisation program, Sortition (Oxford), minimising for time since diagnosis ( $<7$ or $\geq 7$ years), age ( $<55$ or $\geq 55$ years), gender, and trial site. Adults with type 2 diabetes were allocated in a 1:1 ratio to receive automated text message support plus usual care or to usual care supplemented by active control. Allocations were directly uploaded into the trial database to avoid creation of locally held records. Randomisation was carried out remotely and independently of the clinic and local research staff. No arrangements for unblinding during the trial were made. We asked participants not to share the content of their text 
messages and did not recruit more than one participant from the same household. Clinic staff did not have access to information about allocated groups and did not have the facility to send text messages to individuals through the study system. Study procedures were carried out by trained research staff blinded to participant allocation group. Medication dispensing data were collected blind to participant allocation. Study outcomes were assessed by laboratory staff with no knowledge of treatment allocation or by research staff trained not to ask questions that would elicit group allocation.

\section{Intervention}

The intervention was automated and consisted of motivational and educational text-messages sent to participants on different days, three to four times weekly over a period of 12 months. The intervention development process was intended to ensure the final brief (SMS) text-message intervention was theory- and evidence-informed, relevant, and acceptable to the target audiences, and appropriately aligned with the organisation of clinic care at the trial sites. Message content was intended to encourage people to take their medicine regularly as prescribed (70\% of the messages), alongside other information intended to provide advice about healthy lifestyle and enhancing well-being ( $30 \%$ of the messages). Specific messages encouraged people to check the date of their next appointment and whether they had sufficient medication. Message content was developed from lived experience of diabetes, diabetes treatment services and expert opinion and formulated as SMS text-messages. The message development was guided by the Capability, Opportunity, MotivationBehaviour model and described in detail a separate publication $[13,14]$. Messages were translated into Xhosa, Afrikaans, Chichewa and English. Examples of messages used are given in supplementary appendix Table 1 . Messages were randomly selected from a library, using rules that ensured individual messages were not repeated. Messages were personalised by using information given about smoking and use of alcohol to determine whether these messages were sent. Messages were tailored by having participants select the language in which to receive messages, and days on which they did not wish to receive messages. The messaging system allowed participants to change the delivery time or language of messages.

Participants allocated to the usual care group were sent a research related message thanking them for taking part in the study and providing trial related information every 6 weeks.

\section{Procedures}

Both groups received a message welcoming them to the trial; instructions on how to change the phone number to receive messages and how to withdraw from the study, a security reminder that we would never ask for banking or personal information, a "happy birthday" message, and reminders to attend end of study visits. At both study sites, routine clinical care consisted of attendance to collect medication supplies at regular intervals. Routine review appointments were recommended biannually in Cape Town and annually in Lilongwe and included screening for complications associated with type 2 diabetes carried out according to the clinical guidelines in place at the clinic sites. Health material on type 2 diabetes was available at all sites, and included information about the importance of taking medicine regularly, alongside other health information.

Eligible patients attending clinics at both sites were those with type 2 diabetes; aged 18 years or greater; taking an oral glucose-lowering medication; able to communicate in one of the predominant official languages spoken in the Western Cape province in South Africa (English, Afrikaans, or isiXhosa) and in Malawi (English or the Chichewa language); with access to a mobile phone, where shared access is allowed with permission of the phone owner; ability to send and receive, or be helped to send and receive text messages; and current and planned future residence in participating clinic communities. Patients were not eligible for recruitment if they had been admitted to hospital for hyperglycaemia or hypoglycaemia within the previous 3 months; were pregnant or within 3 months postpartum by self-report or with plans to become pregnant in the next 12 months; had been diagnosed with a terminal medical condition; lived with another member of the household already recruited to the trial; or had participated in formative work.

Potential trial participants were approached sequentially by research staff whilst attending scheduled diabetes care sessions at the clinics. They received verbal and written information about the trial in their preferred language and had the opportunity to speak to trained study research staff and ask them questions. Initially, all participants provided verbal assent to screening procedures on agreeing to participate. If eligible, they then all provided written consent for enrolment in the trial. Copies of the consent forms were given to participants and randomisation was not carried out until they confirmed they had received a "welcome" text message.

Trial data collection was carried out using a low-cost mobile phone for data transmission. The phone ran a secure implementation of Sana Mobile (MIT). The Sana Mobile system used secure information exchange protocols to link to a secure server running Open Medical Records System (OpenMRS.org). The use of this system allowed checking of errors in data entry in real-time and enabled data to be immediately uploaded to the trial server.

Participants were invited by SMS text-message to attend the 12-month final trial assessment which was planned to coincide with their routine health care 
review. Participants who did not attend the 12-month follow-up clinic appointment were followed up using the mobile phone and other contact details. If the cause of nonattendance was death, then hospital records were obtained for review.

Data were collected by a team of research assistants trained and supervised to ensure consistency between and within study sites with standard operating procedures for clinical measurement. Data collection took place in clinics, community centres, and in participants homes. Access to end of study data was restricted to data management staff and trial statisticians.

The process evaluation will be reported in detail elsewhere. Briefly, we collected data at both sites using semi structured interviews and focus groups. We used purposive sampling to explore variation in response by variables, including age, gender, and language group of patient participants. We also developed interview guides to explore participant experience and views of receiving SMS text messages doing interviews at baseline (baseline interview guide in supplementary file 2), after enrolment and before a participant is randomised, and in interviews and focus groups with the same group of participants at the end of the trial (final interview guide in supplementary file 3). Trained qualitative researchers conducted the in-depth interviews and focus groups; data was captured with field notes and digital voice recording and was transcribed with anonymisation. Notes and transcripts were coded and themes developed. Standard approaches to ensuring the quality of the methodology were used, including dual review of interview summaries, use of a coding framework, and assessment of samples of dual-coded data.

\section{Deviations from protocol}

Some participants taking insulin but not an oral glucose lowering medication were inadvertently recruited and randomised. These individuals were excluded from the analysis. The planned collection of data and notification of participants where medication was out of stock and tracking of participant attendance to collect medication were not implemented as planned. It emerged during the trial that procedures for dispensing and tracking medication identified in the formative work were no longer being used. We therefore adapted the original planned message to send as a prompt around the time a participant was calculated to require a medication refill, to check the status of their clinic appointment/medication refill. To streamline follow up we made the decision not to record selfreported diet and physical activity measures at follow up.

\section{Outcomes}

We pre-specified change in $\mathrm{HbA1c}$ from baseline to 1 year as the primary outcome. Secondary outcomes were the proportion of patients collecting $80 \%$ or more of their agreed-upon, diabetes-related medication derived from routine clinic data [15]; change in systolic blood pressure; change in lipids; a combined measure of cardiovascular risk based on HbA1c, lipids, and systolic blood pressure [16]; and the proportion of the participants reaching treatment goals $(\mathrm{HbA} 1 \mathrm{c} \leq 8 \%$ and systolic blood pressure $<140 \mathrm{mmHg}$ ).

The EuroQol 5-Dimension 3-Level (EQ-5D-3L) instrument [17], and a locally adapted questionnaire, to establish satisfaction with treatment and delivery of treatment $[18$, 19], were used and available in all of the study languages. In addition, self-reported medication-taking was recorded [20]. Basic demographic data collected included age, gender, language preference, and work status. Anthropometric measures were collected, including measurement of height and weight using standard procedures. Full specification of secondary outcomes and methods of assessment have been previously published [21].

Outcomes of the process evaluation aimed to determine the factors (including individual, health system and broader contextual factors) influencing the impact of the intervention. Detailed economic findings will be reported in a separate paper.

\section{Sample size calculations}

We estimated that a target sample of 1066 adults (including a loss to follow up of $20 \%$ and potential clustering between sites) would provide $90 \%$ power at $5 \%$ level of significance (2-sided) to show a reduction of $0.5 \%$ $(5.5 \mathrm{mmol} / \mathrm{mol})$ in $\mathrm{HbA} 1 \mathrm{c}$, assuming a standard deviation of $2.2 \%(24 \mathrm{mmol} / \mathrm{mol})$.

\section{Statistical analysis}

The study results are reported in accordance with the Consolidated Standards of Reporting Trials (CONSORT) 2010 statements [22]. A full detailed statistical analysis plan was prepared and finalised before participant follow-up was completed.

The results from the trial are presented as comparative summary statistics with $95 \%$ confidence intervals. All the tests were done at a 5\%, two-sided significance level. Analysis of intervention effect was carried out on all participants with non-missing outcome data and participants were analysed in the groups to which they were allocated, regardless of what they actually received, but those randomised but recruited in error, who were not using an oral glucose lowering medication were excluded.

Comparison of change in HbA1c from baseline to 1 year between the intervention and usual care groups used a linear regression model, adjusting for baseline HbA1c and minimising variables. The treatment effect was presented as the adjusted difference between groups 
in the change in HbA1c from baseline, along with a 95\% confidence interval and $P$-value derived from the corresponding t-statistic. Similar methods were used to analyse blood pressure data and other continuous outcomes.

We estimated the proportion of scheduled medication collection appointments successfully completed, in the following way, using routine registers maintained in the clinics. In Cape Town, data were obtained from two sources: (i) record sheets for centrally dispensed medication, delivered to clinics to be picked up by participants were used where marked to indicate collection; (ii) medical records were endorsed where prescriptions were locally dispensed with the participant in attendance. In Lilongwe, the data on participants attending were prospectively collected from clinic records. Records of duration of medication given were not available consistently, we therefore used a conservative estimate of medication being dispensed at three-monthly intervals. We then estimated, for each participant, the proportion of required medication likely to be available over 1 year from the attendance data. The proportions of participants who collected medication on at least $80 \%$ of scheduled occasions were compared using a logbinomial regression model adjusted for minimising variables. The intervention effect was presented as a relative risk with $95 \%$ confidence interval and $P$-value derived from the corresponding Z-statistic.

Missing data were reported with reasons given where available and the missing data pattern and mechanism were explored. We also did a sensitivity analysis using multiple imputation to examine the robustness of the results.

We did pre-specified subgroup analyses of the primary outcome and adherence outcome for the following subgroups: age ( $<55$ years or $\geq 55$ years); site (Cape Town or Lilongwe); gender (male or female); number of years with type 2 diabetes ( $<7$ years or $\geq 7$ years); presence of one or more comorbidity (none, one or more); diabetes control at baseline (HbA1c $\leq 53 \mathrm{mmol} / \mathrm{mol}$ or $>53 \mathrm{mmol} / \mathrm{mol}$ ); and self-reported adherence rating score at baseline (25 or < 25). All statistical analyses were done using Stata version 15.1 (StataCorp LLC, College Station, USA).

\section{Laboratory measurement}

HbA1c was measured using International Federation of Clinical Chemistry calibrated analysers linked to an international quality assurance scheme at both sites. Total and high-density lipoprotein (HDL) cholesterol was analysed using an enzymatic colorimetric method, again with an international quality assurance scheme.

\section{Data management}

Electronic data capture was done with Sana mobile (MIT) using low-cost Android mobile phones and a real-time, mobile Internet connection to a server where the data was stored using OpenMRS [21].

\section{Approvals}

The trial received ethical approval from the University of Oxford Tropical Research Ethics Committee (22-15), the University of Cape Town Human Research Ethics Committee (126/2015) and the Malawi National Health Services Research Committee (15/7/1425). All participants provided informed consent. The trial protocol has been previously published [21].

Data collection, management and analytical procedures were monitored by an independent data monitoring committee. Trial management was also reviewed by an independent trial steering committee.

\section{Results}

Trial recruitment began in September 2016 and follow up of participants finished in October 2018. Of the 1930 potential participants screened, 744 were found to be ineligible.

In total, 1186 participants were randomly allocated to intervention (593) and control (593) (Fig. 1). There were 67 participants recruited who were subsequently identified as ineligible through using insulin alone without an oral glucose lowering drug and these were excluded. Baseline data were collected from all participants with the exception that 21 participants (for example, those in wheelchairs), could not have their weight measured with the measuring devices available.

Baseline characteristics were similar between allocated study groups (Table 1). Mean (SD) age was 57.1 (11.4) years, Body Mass Index $30.7(7.0) \mathrm{kg} / \mathrm{m} 2$, years in school 9.0 (4.0), HbA1c 10.2 (3.5) \%, systolic blood pressure 131.2 (20.4) $\mathrm{mmHg}$, total cholesterol to HDL cholesterol ratio 4.4 (1.6). Of participants, 782 were women (69.9\%) and 568 (50.8\%) were based in Cape Town and 551 (49.2\%) based in Lilongwe. The median (Q1, Q3) duration of diabetes was $5.0(2.8,10.0)$ years, and 10-year risk of coronary heart disease was $9.4(4.7,19.3) \%$. Mean baseline HbA1c differed between sites. The mean (SD) HbA1c for Cape Town was 9.1 (2.3) and for Lilongwe $11.3(4.0) \%$.

The primary outcome was measured in 510 (91.4\%) of those in the intervention group and 512 (91.3\%) of those in the control group. Follow up was similar across both sites.

Exposure to the intervention was high, with a high overall rate of delivery of SMS text messages. Out of a total of 114,207 SMS messages, only 7644 (6.7\%) were not sent from the server or not delivered.

The HbA1c fell in both the intervention and usual care groups, and there was no difference in the change in HbA1c between intervention and usual care groups. The change (reduction) in HbA1c (SD) DCCT [IFCC] from 


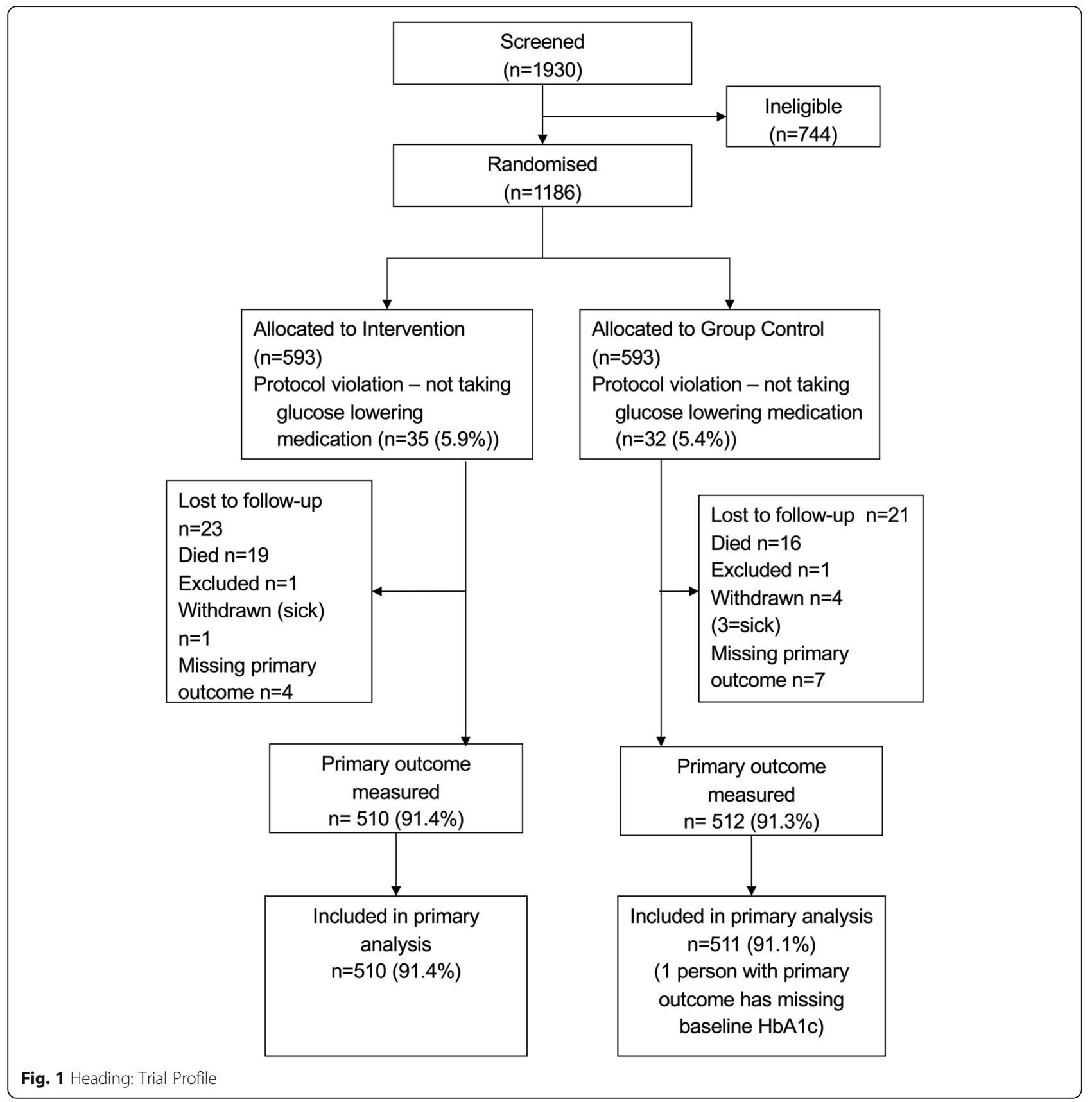

baseline to 1 year was $-1.15(2.81) \%[-12.53$ (30.72) $\mathrm{mmol} / \mathrm{mol}]$ in the intervention group and $-1.19(2.86)$ [- $13.02(31.27) \mathrm{mmol} / \mathrm{mol}]$ in the control group (Fig. 2). The overall adjusted difference in HbA1c (95\% CI) between groups was $-0.08 \%(-0.31$ to 0.16$)[-0.82(-3.44$ to 1.79) $P=0.537]$ in favour of the intervention group. We observed no differences in medication use over time between groups (supplementary tables).

There was a reduction in systolic blood pressure of $0.17 \mathrm{mmHg}$ in the intervention group and a rise of $3.11 \mathrm{mmHg}$ in the control group, with a between group difference of $-3.46 \mathrm{mmHg}(-5.44$ to -1.48 ,
$P=0.001)$ in favour of the intervention group (Table 2). We observed no differences in medication use over time between groups (supplementary tables). The corresponding difference in change in 10-year risk of coronary heart disease was $-0.71 \%(-1.46$ to $0.04, P=0.064)$. The proportion of participants meeting treatment goals at one-year in the intervention group was $36.0 \%$ and in the control group $26.8 \%$ (Relative risk 1.36 (1.13 to $1.63, P=0.001$ ). There were no other clinically important between group differences in the clinical, self-report measures of medication use and satisfaction. 
Table 1 Baseline data

\begin{tabular}{|c|c|c|c|}
\hline & $\begin{array}{l}\text { Intervention } \\
n=558\end{array}$ & $\begin{array}{l}\text { Control } \\
n=561\end{array}$ & $\begin{array}{l}\text { Overall } \\
n=1119\end{array}$ \\
\hline \multicolumn{4}{|l|}{ Gender, n(\%) } \\
\hline Female & $390(69.9)$ & $392(69.9)$ & $782(69.9)$ \\
\hline Male & $168(30.1)$ & $169(30.1)$ & $337(30.1)$ \\
\hline \multicolumn{4}{|l|}{${ }^{\mathrm{a}}$ Age (years), n(\%) } \\
\hline$<55$ years & $229(41.0)$ & $236(42.1)$ & $465(41.6)$ \\
\hline$\geq 55$ years & $328(58.8)$ & $324(57.8)$ & $652(58.3)$ \\
\hline Missing & $1(0.2)$ & $1(0.2)$ & $2(0.2)$ \\
\hline \multicolumn{4}{|l|}{ Age (years) } \\
\hline Mean (SD) & $56.8(11.6)$ & $57.4(11.1)$ & $57.1(11.4)$ \\
\hline Range & 24.8 to 97.0 & 28.7 to 89.6 & 24.8 to 97.0 \\
\hline Missing & 1 & 1 & 2 \\
\hline \multicolumn{4}{|l|}{ Site, $n(\%)$} \\
\hline Cape Town, SA & $276(49.5)$ & $292(52.1)$ & $568(50.8)$ \\
\hline Lilongwe, Malawi & $282(50.5)$ & $269(48.0)$ & $551(49.2)$ \\
\hline \multicolumn{4}{|c|}{${ }^{\mathrm{a}}$ Duration of diabetes (years), $\mathrm{n}(\%)$} \\
\hline$<7$ years & $333(59.7)$ & $332(59.2)$ & $665(59.4)$ \\
\hline$\geq 7$ years & $224(40.1)$ & $228(40.6)$ & $452(40.4)$ \\
\hline Missing & $1(0.2)$ & $1(0.2)$ & $2(0.2)$ \\
\hline \multicolumn{4}{|l|}{ Duration of diabetes (years) } \\
\hline Median & 5.0 & 5.2 & 5 \\
\hline IQR & 2.5 to 10 & 3 to 10.0 & 2.8 to 10 \\
\hline Missing & 1 & 1 & 2 \\
\hline \multicolumn{4}{|l|}{ Years in school/education } \\
\hline Mean (SD) & $9.0(3.9)$ & $9.1(4.2)$ & $9,0(4.0)$ \\
\hline Missing & 1 & 1 & 2 \\
\hline \multicolumn{4}{|l|}{ Currently smoke, n(\%) } \\
\hline Yes & $68(12.2)$ & $72(12.8)$ & $140(12.5)$ \\
\hline No & $489(87.6)$ & $488(87.0)$ & $977(87.3)$ \\
\hline Missing & $1(0.2)$ & $1(0.2)$ & $2(0.2)$ \\
\hline \multicolumn{4}{|c|}{ Currently use smokeless tobacco, $\mathrm{n}(\%)$} \\
\hline Yes & $22(3.9)$ & $21(3.7)$ & $43(3.8)$ \\
\hline No & $535(95.9)$ & $539(96.1)$ & $1074(96.0)$ \\
\hline Missing & $1(0.2)$ & $1(0.2)$ & $2(0.2)$ \\
\hline \multicolumn{4}{|l|}{ Tobacco Frequency, $\mathrm{n}(\%)$} \\
\hline Less than once a week & $546(97.9)$ & $544(97.0)$ & $1090(97.4)$ \\
\hline Twice a week & 0 & $2(0.4)$ & $2(0.2)$ \\
\hline 3 to 5 times a week & 0 & $2(0.4)$ & $2(0.2)$ \\
\hline Every or almost every day & $7(1.3)$ & $9(1.6)$ & $16(1.4)$ \\
\hline More than once a day & $4(0.7)$ & $3(0.5)$ & $7(0.6)$ \\
\hline Missing & $1(0.2)$ & $1(0.2)$ & $2(0.2)$ \\
\hline \multicolumn{4}{|l|}{ Live with a smoker, $\mathrm{n}(\%)$} \\
\hline Yes & $157(28.1)$ & $154(27.5)$ & $311(27.8)$ \\
\hline No & $399(71.5)$ & $402(71.7)$ & $801(71.2)$ \\
\hline
\end{tabular}


Table 1 Baseline data (Continued)

\begin{tabular}{|c|c|c|c|}
\hline & $\begin{array}{l}\text { Intervention } \\
n=558\end{array}$ & $\begin{array}{l}\text { Control } \\
n=561\end{array}$ & $\begin{array}{l}\text { Overall } \\
n=1119\end{array}$ \\
\hline Unsure & $1(0.2)$ & $4(0.7)$ & $5(0.5)$ \\
\hline Missing & $1(0.2)$ & $1(0.2)$ & $2(0.2)$ \\
\hline \multicolumn{4}{|l|}{$\mathrm{BP}(\mathrm{mmHg})$} \\
\hline Systolic, Mean (SD) & $130.6(20.4)$ & $131.7(20.4)$ & $131.2(20.4)$ \\
\hline Diastolic, Mean (SD) & $78.3(10.9)$ & $79.0(11.4)$ & $78.7(11.1)$ \\
\hline Missing & 1 & 2 & 3 \\
\hline \multicolumn{4}{|l|}{ BMI $\left(\mathrm{kg} / \mathrm{m}^{2}\right)$} \\
\hline Mean (SD) & $30.6(6.5)$ & $30.8(7.4)$ & $30.7(7.0)$ \\
\hline Missing & 8 & 12 & 20 \\
\hline \multicolumn{4}{|l|}{ HbA1c (\%) } \\
\hline Mean (SD) & $10.1(3.4)$ & $10.2(3.6)$ & $10.2(3.5)$ \\
\hline Missing & 1 & 3 & 4 \\
\hline \multicolumn{4}{|l|}{$\mathrm{HbA1c}(\mathrm{mmol} / \mathrm{mol})$} \\
\hline Mean (SD) & $87.1(36.8)$ & $88.4(38.9)$ & $87.7(37.8)$ \\
\hline Missing & 1 & 3 & 4 \\
\hline \multicolumn{4}{|l|}{ HDL Cholesterol (mmol/l) } \\
\hline Mean (SD) & $1.2(0.4)$ & $1.2(0.3)$ & $1.2(0.3)$ \\
\hline Missing & 1 & 2 & 3 \\
\hline \multicolumn{4}{|l|}{ Total Cholesterol (mmol/l) } \\
\hline Mean (SD) & $4.9(1.3)$ & $4.9(1.3)$ & $4.9(1.3)$ \\
\hline Missing & 4 & 4 & 8 \\
\hline \multicolumn{4}{|c|}{ Ratio of HDL to Total Cholesterol } \\
\hline Mean (SD) & $0.25(0.09)$ & $0.25(0.08)$ & $0.25(0.08)$ \\
\hline Missing & 4 & 4 & 8 \\
\hline \multicolumn{4}{|l|}{ SMS Language, n(\%) } \\
\hline Chichewa & $252(45.2)$ & $246(43.9)$ & $498(44.5)$ \\
\hline Isixhosa & 109 (19.5) & $108(19.3)$ & $217(19.4)$ \\
\hline English & $112(20.1)$ & $120(21.4)$ & $232(20.7)$ \\
\hline Afrikaans & $84(15.1)$ & $86(15.3)$ & $170(15.2)$ \\
\hline Missing & $1(0.18)$ & $1(0.18)$ & $2(0.18)$ \\
\hline \multicolumn{4}{|l|}{ Current health, n(\%) } \\
\hline Poor & $44(7.9)$ & $52(9.3)$ & $96(8.6)$ \\
\hline Fair & $163(29.2)$ & $172(30.7)$ & $335(29.9)$ \\
\hline Good & $303(54.3)$ & $291(51.9)$ & $594(53.1)$ \\
\hline Excellent & $47(8.4)$ & $45(8.0)$ & $92(8.2)$ \\
\hline Missing & $1(0.18)$ & $1(0.18)$ & $2(0.18)$ \\
\hline \multicolumn{4}{|l|}{ Medication use, $\mathrm{n}(\%)$} \\
\hline Insulin & $91(16.3)$ & $102(18.2)$ & $193(17.3)$ \\
\hline Statin & $216(38.7)$ & $243(43.3)$ & $459(41.0)$ \\
\hline Metformin & $527(94.4)$ & $528(94.1)$ & $1055(94.3)$ \\
\hline Sulfonylurea & $396(71.0)$ & $378(67.4)$ & $774(69.2)$ \\
\hline Pioglitazone & 0 & 0 & 0 \\
\hline BP lowering medication & $394(70.6)$ & $416(74.2)$ & $810(72.4)$ \\
\hline
\end{tabular}


Table 1 Baseline data (Continued)

\begin{tabular}{|c|c|c|c|}
\hline & $\begin{array}{l}\text { Intervention } \\
n=558\end{array}$ & $\begin{array}{l}\text { Control } \\
n=561\end{array}$ & $\begin{array}{l}\text { Overall } \\
n=1119\end{array}$ \\
\hline Missing & $1(0.18)$ & $1(0.18)$ & $2(0.18)$ \\
\hline \multicolumn{4}{|l|}{ MARS- $5^{\mathrm{b}}$} \\
\hline Mean (SD) & $22.7(2.6)$ & $22.7(2.8)$ & $22.7(2.7)$ \\
\hline Missing & 1 & 1 & 2 \\
\hline \multicolumn{4}{|l|}{ EQ5D-3 L Index Value } \\
\hline Mean (SD) & $0.78(0.26)$ & $0.78(0.27)$ & $0.78(0.26)$ \\
\hline Missing & 1 & 1 & 2 \\
\hline \multicolumn{4}{|l|}{ Satisfaction with health care } \\
\hline Mean (SD) & $4.2(0.8)$ & $4.2(0.8)$ & $4.2(0.8)$ \\
\hline Missing & 1 & 1 & 2 \\
\hline \multicolumn{4}{|l|}{ Self-reported eating } \\
\hline Mean (SD) & $11.8(4.9)$ & $11.4(5.0)$ & $11.6(4.9)$ \\
\hline Missing & 1 & 1 & 2 \\
\hline \multicolumn{4}{|l|}{ Self-reported physical activity } \\
\hline Mean (SD) & $7.4(6.0)$ & $6.7(5.8)$ & $7.0(5.9)$ \\
\hline Missing & 1 & 1 & 2 \\
\hline \multicolumn{4}{|c|}{ 10-year coronary heart disease risk (\%) } \\
\hline Median & 9.1 & 9.6 & 9.4 \\
\hline IQR & 4.4 to 19.4 & 4.8 to 19.3 & 4.7 to 19.3 \\
\hline Missing & 4 & 6 & 10 \\
\hline \multicolumn{4}{|c|}{ Number of glucose lowering medications prescribed } \\
\hline Mean (SD) & $1.8(0.5)$ & $1.8(0.5)$ & $1.8(0.5)$ \\
\hline Median (IQR) & 2 (2 to 2$)$ & $2(1$ to 2$)$ & 2 (2 to 2$)$ \\
\hline Missing & 1 & 2 & 3 \\
\hline \multicolumn{4}{|c|}{ Number of blood pressure lowering medications prescribed } \\
\hline Mean (SD) & $1.5(1.2)$ & $1.5(1.2)$ & $1.5(1.2)$ \\
\hline Median (IQR) & $2(0$ to 2$)$ & 2 (0 to 2$)$ & $2(0$ to 2$)$ \\
\hline Missing & 1 & 2 & 3 \\
\hline \multicolumn{4}{|c|}{ Number of cholesterol lowering medications prescribed } \\
\hline Mean (SD) & $0.4(0.5)$ & $0.4(0.5)$ & $0.4(0.5)$ \\
\hline Median (IQR) & $0(0$ to 1$)$ & $0(0$ to 1$)$ & $0(0$ to 1$)$ \\
\hline Missing & 1 & 2 & 3 \\
\hline \multicolumn{4}{|l|}{ Comorbidities, n(\%) } \\
\hline Heart attack & $36(6.5)$ & $28(5.0)$ & $64(5.7)$ \\
\hline Heart failure & $28(5.0)$ & $20(3.4)$ & $48(4.3)$ \\
\hline TIA/mini stroke & $45(8.1)$ & $41(7.3)$ & $86(7.7)$ \\
\hline Angina/chest pain & $50(9.0)$ & $41(7.3)$ & $91(8.1)$ \\
\hline Peripheral vascular disease & $79(14.2)$ & $65(11.6)$ & $144(12.9)$ \\
\hline Chronic kidney disease & $21(3.8)$ & $18(3.2)$ & $39(3.5)$ \\
\hline TB & $47(8.4)$ & $58(10.3)$ & $105(9.4)$ \\
\hline Mental Illness & $25(4.5)$ & $29(5.2)$ & $54(4.8)$ \\
\hline
\end{tabular}

${ }^{a}$ Variables used in minimisation

${ }^{\mathrm{b}}$ Medication adherence report scale 


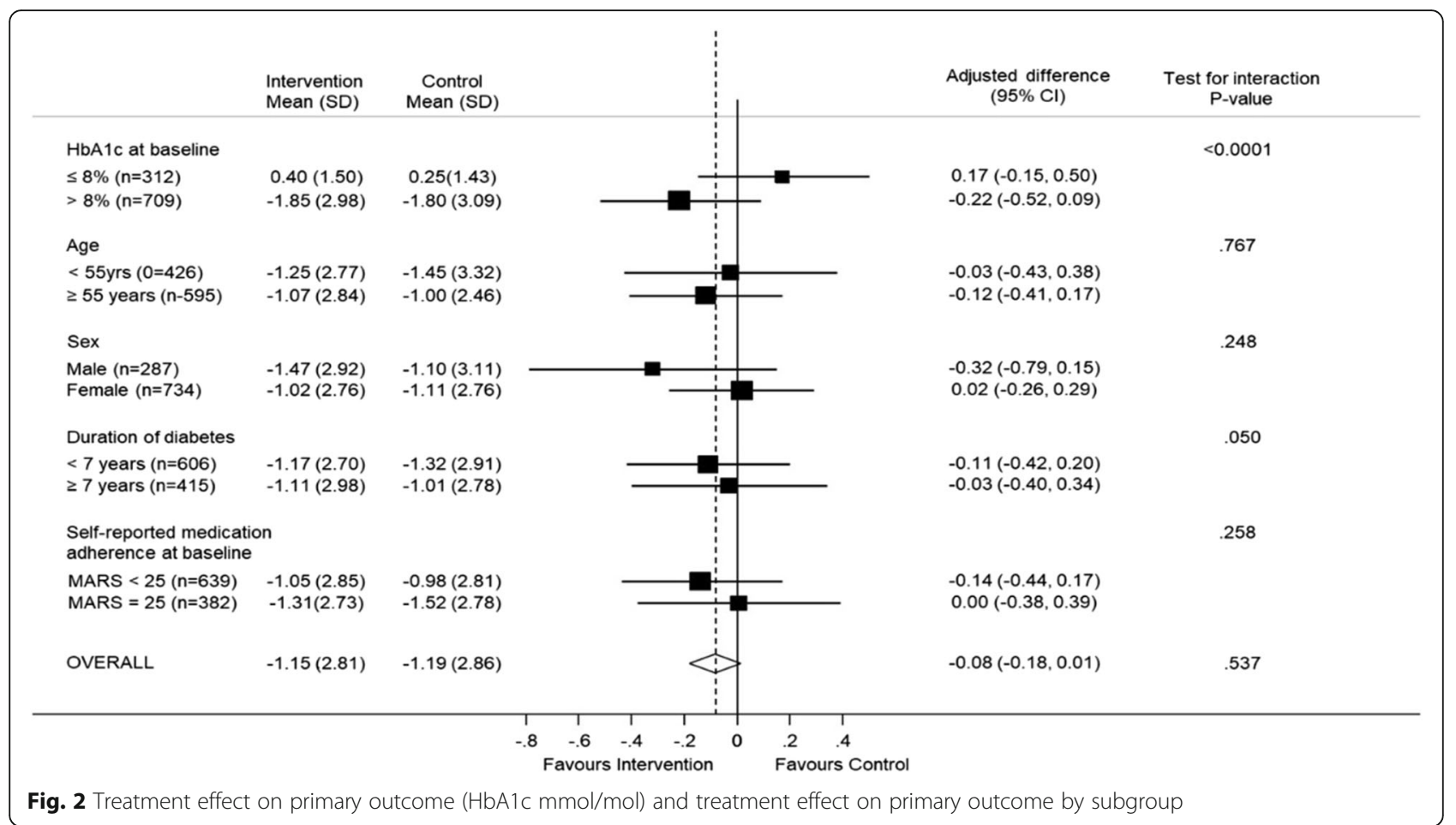

There was no evidence of impact on the secondary outcome of medication adherence. Our pre-specified cut-off for adherence of attending at least $80 \%$ of scheduled medication collection appointments was met by only $15.7 \%$ of the intervention group and $14.2 \%$ of the control group (Relative risk $1.11(0.84$ to $1.47 ; P=0.47$ ). In addition, we carried out an exploratory analysis of adherence using continuous data. This did not change the conclusion with a mean (SD) percentage of the proportion of diabetes-related medication collected over 1 year of 56.7 (23.0)\% for the intervention group and 54.2 (23.0)\% for usual care $(P=0.061)$.
The pre-specified subgroup analyses (Table 3 and Fig. 2) for HbA1c outcomes suggests an interaction between change in $\mathrm{HbA1c}$ for those with a HbA1c $>53$ $\mathrm{mmol} / \mathrm{mol}$ and $\leq 53 \mathrm{mmol} / \mathrm{mol}$. There is a difference between intervention and control of HbA1c (DCCT) in favour of intervention of $-1.85 \mathrm{mmol} / \mathrm{mol}$ for $\mathrm{HbA} 1 \mathrm{c}>$ $53 \mathrm{mmol} / \mathrm{mol}$ and a difference of $0.4 \mathrm{mmol} / \mathrm{mol}$ in favour of control for $\leq 53 \mathrm{mmol} / \mathrm{mol}$ ( $P$-value interaction $<0.0001)$. There was a marginal interaction for change in HbA1c by duration of diabetes $(P=0.05)$. There was no evidence of interactions for diabetes control, by site, age, gender, or presence of comorbidities. There were 19

Table 2 Treatment effect on secondary outcomes

\begin{tabular}{|c|c|c|c|c|}
\hline \multicolumn{5}{|l|}{ Outcomes } \\
\hline & \multicolumn{4}{|c|}{ Change from baseline to 12 months } \\
\hline & Intervention & Control & Mean difference & $P$ \\
\hline Systolic blood pressure & $-0.17(18.9)$ & $3.11(19.24)$ & $-3.46(-5.44$ to -1.48$)$ & 0.001 \\
\hline Total/HDL cholesterol & $-0.03(1.3)$ & $0.01(1.1)$ & $-0.03(-0.17$ to 0.10$)$ & 0.633 \\
\hline Body mass index (kg/m2) & $0.03(2.14)$ & $-0.07(3.76)$ & $-0.08(-0.45$ to 0.29$)$ & 0.669 \\
\hline Modelled cardiovascular risk & $-1.24(8.22)$ & $-0.38(7.94)$ & $-0.71(-1.46$ to 0.041$)$ & 0.064 \\
\hline Health status EQ-5D & $0.009(0.160)$ & $-0.004(0.157)$ & $-0.011(-0.007$ to 0.030$)$ & 0.202 \\
\hline Medication taking (MARS) & $0.6(2.81)$ & $0.37(3.18)$ & $-0.26(-0.03$ to 0.54$)$ & 0.075 \\
\hline \multirow[t]{2}{*}{ Satisfaction with health care } & $0.27(0.74)$ & $0.21(0.74)$ & $-0.030(-0.038$ to 0.099$)$ & 0.385 \\
\hline & Intervention & Control & Relative Risk (95\% Cl) & $P$ \\
\hline Reaching treatment goals & $182(36.0)$ & $136(26.8)$ & $1.36(1.13$ to 1.63$)$ & 0.001 \\
\hline$\geq 80 \%$ visits for medication collection & $87(15.7)$ & $79(14.2)$ & 1.11 (0.84 to 1.47$)$ & 0.469 \\
\hline
\end{tabular}

Data on self-reported dietary intake and physical activity was not recorded at follow up 
Table 3 Treatment effect on primary outcome and treatment effect on primary outcome by subgroup

\begin{tabular}{|c|c|c|c|c|}
\hline \multicolumn{5}{|c|}{ Change in $\mathrm{HbA} 1 \mathrm{c}(\mathrm{mmol} / \mathrm{mol})$ from baseline to 12 months } \\
\hline & Intervention $^{\mathrm{a}}$ & Control $^{\mathrm{a}}$ & Mean difference $^{b}$ & $\mathbf{P}$ \\
\hline $\mathrm{HbA1c}(\mathrm{mmol} / \mathrm{mol})$ & $-12.5(30.72)$ & $-13.0(31.27)$ & $-0.82(-3.44$ to 1.79$)$ & 0.537 \\
\hline \multicolumn{5}{|l|}{ HbAlc at baseline } \\
\hline$\leq 64 \mathrm{mmol} / \mathrm{mol}$ & $4.4(16.39)$ & $2.7(15.68)$ & $1.89(-1.68$ to 5.46$)$ & \multirow[t]{2}{*}{$<0.0001$} \\
\hline$>64 \mathrm{mmol} / \mathrm{mol}$ & $-20.3(32.59)$ & $-19.7(33.76)$ & $-2.36(-5.70$ to 0.97$)$ & \\
\hline \multicolumn{5}{|l|}{ Age } \\
\hline$<55$ years & $-13.7(30.29)$ & $-15.8(36.32)$ & $-0.28(-4.70$ to 4.14$)$ & \multirow[t]{2}{*}{0.767} \\
\hline$\geq 55$ years & $-11.7(31.05)$ & $-11.0(26.90)$ & $-1.30(-4.50$ to 1.90$)$ & \\
\hline \multicolumn{5}{|l|}{ Gender } \\
\hline Male & $-16.1(31.88)$ & $-15.3(33.96)$ & $-3.47(-8.61$ to 1.67$)$ & \multirow[t]{2}{*}{0.248} \\
\hline Female & $-11.1(30.18)$ & $-12.1(30.17)$ & $0.17(-2.88$ to 3.22$)$ & \\
\hline \multicolumn{5}{|l|}{ Duration of diabetes } \\
\hline$<7$ years & $-12.8(29.48)$ & $-14.4(31.86)$ & $-1.20(-4.62$ to 2.22$)$ & \multirow[t]{2}{*}{0.050} \\
\hline$\geq 7$ years & $-12.2(32.53)$ & $-11.0(30.37)$ & $-0.37(-4.42$ to 3.68$)$ & \\
\hline \multicolumn{5}{|c|}{ Self-reported medication adherence at baseline } \\
\hline MARS $<25$ & $-11.5(31.18)$ & $-10.7(30.74)$ & $-1.51(-4.86$ to 1.84$)$ & \multirow[t]{2}{*}{0.258} \\
\hline MARS $=25$ & $-14.4(29.85)$ & $-16.6(31.83)$ & $0.05(-4.18$ to 4.29$)$ & \\
\hline
\end{tabular}

${ }^{\mathrm{a} M e a n}(\mathrm{SD})$

${ }^{\mathrm{b}}$ Mean $(95 \% \mathrm{Cl})$

(3.4\%) deaths in the intervention group and 16 (2.9\%) deaths in the control group. There were no adverse events related to the trial intervention.

\section{Process evaluation}

Details of our qualitative findings will be reported elsewhere. In summary, participants in the intervention arm of the trial found brief text messaging for diabetes adherence acceptable and useful for addressing informational and support needs. There were some examples of positive behaviour change reported due to the text reminders and advice on healthy lifestyle. There was a strong relational effect with messages and trial participation being experienced as a source of support, caring and motivation. However, participants' ability to act on the messages was limited, against a background of navigating a complex set of challenges in coping with their diabetes and other life challenges. Impact and participant responses were similar across sites, despite socio-economic and health service differences. Common themes were participants' frustration over how unstable their health was, their struggle to control their blood glucose levels, and their need for more responsive health care.

\section{Costs}

The annualised economic cost of the study intervention amounted to $\$ 7883$ in the Malawi clinic and \$6336 in the South African clinic. Fixed costs (formative research, set-up, and programming) represented respectively 72 and $83 \%$ of these costs. This difference is largely explained by the fact that the cost of SMS text-messages in Malawi is twice the cost of SMS in South-Africa. If the intervention was scaled-up and rolled out to $90 \%$ of adults with diabetes on treatment in each country, the shares of fixed costs decrease very significantly to $1.33 \%$ in Malawi and $0.04 \%$ in South-Africa, the largest cost becoming that of the SMS text-messages. The annualised cost of the intervention per diabetes patient year would amount to \$6.47 in Malawi and \$3.16 in South-Africa. The cost per patient year of routine treatment is $\$ 58.58$ and $\$ 189.96$ respectively. Including the intervention as part of routine treatment would thus increase the cost per patient year by $11.05 \%$ in Malawi and 1.66\% in South Africa. Costs to patients affect adherence. For patients using private and public transport, (95\% in Lilongwe and $42 \%$ in Cape Town) transport cost per visit was the equivalent of 5 loaves of bread in Lilongwe and 2.5 in Cape Town. Time in clinic was significant, mainly due to waiting time. It was an average of $2.5 \mathrm{~h}$ in Lilongwe and just under $5 \mathrm{~h}$ in Cape Town.

\section{Discussion}

The StAR2D trial does not provide convincing evidence that well-designed text messages lead to changes in glycaemic control across the range of baseline HbA1c for people with type 2 diabetes and across two low resource settings in urban sub Saharan Africa, but there is 
evidence for a significant and clinically important impact on blood pressure and attainment of treatment goals in this population, although the reasons for a difference in impact on glycaemia and blood pressure are unclear. Findings were similar between two contrasting settings. The process evaluation suggested that the SMS messages were seen as relevant and useful, providing examples of behaviour change, although messages did not appear to address the complex reasons underlying ongoing partial adherence behaviours or the clinical need for escalating treatment. Set-up costs per patient become minimal when the intervention is scaled up. Then the main cost driver is that of cost per SMS message in the country.

We compared our study to those included in at least one of three recent meta-analyses of SMS texts to support people with diabetes [23-25]. We found most of the studies included were small (100 participants or less) of short duration (3 to 6 months), focused on people with poorly controlled HbA1c levels (defined as a HbA1c $>7 \%$ ) and compared intervention to usual care, although usual care varied across studies. There was variation in the content and dosage of the intervention but no obvious dose-response pattern. In most of the studies, both intervention and control arms showed a fall in the level of HbA1c including those studies where the between group difference was not significant which is consistent with our findings. It is possible that willingness to take part in a trial may also be associated with changes in motivation relating to medication use and other lifestyle behaviours. Larger studies and those carried out over a longer period did not identify statistically significant differences in measures of $\mathrm{HbA1c}$ between intervention and control groups [23-25], with one widely reported exception [26]. This nine-month New Zealand study differed from ours, in that the participants were people with type 1 and type 2 diabetes, who were using oral glucose lowering medication and insulin and the intervention included graphical feedback of blood glucose readings [26]. The closed-loop communication between participants and providers in the New Zealand study may have enhanced the impact of the intervention. We involved clinicians in the design of the messaging system, but not, in day to day interaction with patients as this would not have been feasible either in our local context or to scale more widely. We observed that this may have reduced our agility in responding to local context.

The trial setting is representative of outpatient clinical care available for most people with type 2 diabetes in LMIC. The level of HbA1c in the population was high in both sites and despite the long duration of type 2 diabetes, many people were still on oral monotherapy and had not been prescribed additional treatment. The numbers of people who died during the 1 year of the trial emphasises the extent of morbidity and mortality in this population.

Our results showed mixed effects on outcomes that are important for people with type 2 diabetes. For example, we observed a similar, though larger effect of the intervention on lowering blood pressure than that reported in a previous study using SMS text-messaging to support the regular use of medication [27], but there was no similar impact on HbA1c. Some of the messages focussed on cardiovascular risk factors and cardiovascular disease prevention. In pre-specified sub-group analyses, we found evidence of interaction by the level of $\mathrm{HbA} 1 \mathrm{c}$ at the start of the trial and by the duration of diabetes (self-reported time since diagnosis). The results suggest that it is possible that people with higher starting HbA1c and shorter duration of disease may have benefitted more from the intervention than those with lower baseline $\mathrm{HbA} 1 \mathrm{c}$ or longer duration of disease. However, the effect is small and the mean difference in HbAlc is not non clinically relevant. These results show the limited scope for an effect from SMS text-messages on glycaemic control in the absence of treatment intensification or increased levels of support.

A cost-effectiveness analysis had originally been planned. However, findings showed no difference between intervention and control groups for the main outcome of the study and no difference in EQ-5D measures, so this analysis has not been done.

StAR2D tested at scale, the use of brief messages delivered by SMS text-message for improving outcomes for people with type 2 diabetes. HbA1c and blood pressure outcomes were collected blind to randomly allocated group and with minimal loss to follow up. The design of the study excluded interim $\mathrm{HbA1c}$ measures that may have identified an early, but transient change in HbAlc level (potentially at the expense of modifying the impact of the trial interventions) in contrast to other shorter-term studies. We did not, for similar reasons, have additional measures in place to self-report whether messages were read, but our formative work did not indicate this would be a problem, we tracked whether participants were receiving messages on their mobile phones, and they reported receiving and reading them in interviews after the trial had finished. We did not measure health literacy as a dependent variable and did not measure whether people had the messages read to them, but most participants interviewed in our qualitative study had basic knowledge, although lacked personal information about what might be needed to stabilise their blood sugar.

This trial provided a good test of the pragmatic impact of messaging without additional support beyond usual clinic care. As a test of efficacy, this study was limited by wide inclusion criteria including participants with comorbid conditions and those with a varied degree of 
glycaemic control. The study builds on previous work [27], with an increased frequency of sending messages and a message library utilising a wide range of behaviour-change techniques and an increased number of content domains [28].

\section{Conclusions}

In this large, robust, randomised trial in two subSaharan African cities, we did not find convincing evidence that well-designed text messages lead to changes in glycaemic control for people with type 2 diabetes receiving usual primary care, although there was evidence for a clinically important impact on blood pressure and attainment of treatment goals. Text messages alone [11], may be unsuccessful in achieving glycaemic control unless accompanied by multi-modal health system strengthening and other forms of support for selfmanagement. Further work is needed on what health service and self-management components are needed in combination with targeted digital communication using a wider range of approaches, to support diabetes adherence behaviour.

\begin{abstract}
Abbreviations
CONSORT: Consolidated Standards of Reporting Trials; EQ-5D-3L: EuroQol 5Dimension 3-Level; HbA1c: Hemoglobin A1c; HDL: High-density lipoprotein; ICH GCP: International Conference on Harmonisation of Technical

Requirements for Registration of Pharmaceuticals for Human Use-Good Clinical Practice; ICMJE: International Committee of Medical Journal Editors; ITT: Intention-to-treat; NHSRC: National Health Services Research Committee; OpenMRS: Open Medical Records System; OXTREC: University of Oxford Tropical Research Ethics Committee; SMS: Short message service; StAR2D: SMS-Text Adherence Support for Type 2 Diabetes; StAR-BP: SMS-Text Adherence Support-Blood Pressure; UCT HREC: University of Cape Town Research Ethics Committee
\end{abstract}

\section{Supplementary Information}

The online version contains supplementary material available at https://doi. org/10.1186/s12889-021-11874-7.

Additional file 1. Collaborating Centres and supplementary data table.

Additional file 2. Baseline process evaluation interview guide.

Additional file 3. Final process evaluation interview guide.

\section{Acknowledgements}

Not applicable.

\section{Authors' contributions}

$A F, K B$, and $N L$ were responsible for the study conception and design. AF, $K B, N L, N a L, L T, S N, M N, A C, D B, E D$ and $L-M Y$ were responsible for drafting the protocol. NL, SC, HN, JP, DS, KB, AF, LT, EP, BP, and JN were responsible for the intervention development. $E P, H N, N L, A C, S C, J N, B P$ were involved in data collection. L-MY, NW, JP, DS, AF, and KB were responsible for data management and statistics and analysis. AF, KB, NL, NaL and AC were responsible for interpretation of findings. First draft of the manuscript was drafted by AF and KB. Edit and approval AF, KB, NaL, NW, EP, HN, SC, JP, AC, $D B, E D, L-M Y, J N, D S, B P, S N, L T, M N, N L$.

\section{Funding}

The trial was funded by the UK Medical Research Council (MR/M016498/1)) with the South African Medical Research Council under the Global Alliance for Chronic Disease Diabetes Programme. The trial sponsor was the Joint Research
Office, University of Oxford, UK. The funder had no role in the design, execution, analyses, interpretation of the data, or decision to submit results. AF \& LT were supported by the National Institute for Health Research (NIHR) Oxford Biomedical Research Centre (BRC). The views expressed are those of the author(s) and not necessarily those of the NHS, the NIHR or the Department of Health.

\section{Availability of data and materials}

The datasets used and analysed are available from the corresponding author on reasonable request.

\section{Declarations}

\section{Ethics approval and consent to participate}

The trial received ethical approval from the University of Oxford Tropical Research Ethics Committee (22-15), the University of Cape Town Human Research Ethics Committee (126/2015) and the Malawi National Health Services Research Committee (15/7/1425). All participants provided written informed consent.

\section{Consent for publication}

Not applicable.

\section{Competing interests}

None to declare.

\section{Author details}

${ }^{1}$ Nuffield Department of Primary Care Health Sciences, University of Oxford, Oxford, UK. ${ }^{2}$ Chronic Disease Initiative for Africa, University of Cape Town, Cape Town, South Africa. ${ }^{3}$ Health Systems Research Unit, South-African Medical Research Council, Cape Town, South Africa. ${ }^{4}$ Malawi Epidemiology and Intervention Research Unit, Lilongwe, Malawi. ${ }^{5}$ Cochrane South Africa, South African Medical Research Council, Cape Town, South Africa. ${ }^{\circ}$ Institute of Biomedical Engineering, Oxford, UK. ${ }^{7}$ Kamuzu Central Hospital, Lilongwe, Malawi. ${ }^{8}$ Boston Consulting Group, London, UK. ${ }^{9}$ Department of Diabetes and Endocrinology, Chris Hani Baragwanath Academic Hospital, Johannesburg, South Africa. ${ }^{10}$ Human Nutrition Unit, South African Medical Research Council, Johannesberg, South Africa.

Received: 10 October 2020 Accepted: 28 September 2021 Published online: 21 October 2021

\section{References}

1. Bertram MY, Jaswal AVS, Van Wyk VP, Levitt NS, Hofman KJ. The non-fatal disease burden caused by type 2 diabetes in South Africa, 2009. Glob Health Action. 2013;6(1):19244. https://doi.org/10.3402/gha.v6i0.19244

2. Peer, N., Steyn, K., Lombard, C., one, E. L. P. Rising diabetes prevalence among urban-dwelling black South Africans. 2012. journals.plos.org.

3. Msyamboza KP, Mvula CJ, Kathyola D. Prevalence and correlates of diabetes mellitus in Malawi: population-based national NCD STEPS survey. BMC Endocr Disord. 2014;14(1):41. https://doi.org/10.1186/1472-6823-14-41.

4. Owolabi MO, Yaria JO, Daivadanam M, Makanjuola Al, Parker G, Oldenburg $B$, et al. Gaps in guidelines for the management of diabetes in low- and middle-income versus high-income countries - a systematic review. Diabetes Care. 2018;41(5):1097-105. https://doi.org/10.2337/dc17-1795.

5. Pound P, Britten N, Morgan M, Yardley L, Pope C, Daker-White G, et al. Resisting medicines: a synthesis of qualitative studies of medicine taking. Soc Sci Med. 2005;61 (1):133-55. https://doi.org/10.1016/j.socscimed.2004.11.063.

6. Pladevall $\mathrm{M}$, et al. Clinical outcomes and adherence to medications measured by claims data in patients with diabetes. Diabetes Care. 2004;27: 2800-5.

7. Asche C, LaFleur J, Conner C. A review of diabetes treatment adherence and the association with clinical and economic outcomes. Clin Ther. 2011; 33(1):74-109. https://doi.org/10.1016/j.clinthera.2011.01.019.

8. Farmer AJ, McSharry J, Rowbotham S, McGowan L, Ricci-Cabello I, French DP. Effects of interventions promoting monitoring of medication use and brief messaging on medication adherence for people with type 2 diabetes: a systematic review of randomized trials. Diabet Med. 2015;33(5):565-79. https://doi.org/10.1111/dme.12987.

9. Ramachandran A, Snehalatha C, Ram J, Selvam S, Simon M, Nanditha A, et al. Effectiveness of mobile phone messaging in prevention of type 2 
diabetes by lifestyle modification in men in India: a prospective, parallelgroup, randomised controlled trial. Lancet Diabetes Endocrinol. 2013;1(3): 191-8. https://doi.org/10.1016/S2213-8587(13)70067-6.

10. Free C, Phillips G, Galli L, Watson L, Felix L, Edwards P, et al. The effectiveness of mobile-health technology-based health behaviour change or disease management interventions for health care consumers: a systematic review. PLoS Med. 2013;10(1):e1001362. https://doi.org/10.1371/ journal.pmed.1001362.

11. Owolabi EO, Goon DT, Ajayi Al. Efficacy, acceptability and feasibility of daily text-messaging in promoting glycaemic control and other clinical outcomes in a low-resource setting of South Africa: a randomised controlled trial. PLoS One. 2019;14(11):e0224791-17. https://doi.org/10.1371/journal.pone.0224791.

12. Bloomfield GS, Vedanthan R, Vasudevan L, Kithei A, Were M, Velazquez EJ. Mobile health for non-communicable diseases in sub-Saharan Africa: a systematic review of the literature and strategic framework for research. Glob Health. 2014;10(1):49. https://doi.org/10.1186/1744-8603-10-49.

13. Michie S, van Stralen MM, West R. The behaviour change wheel: a new method for characterising and designing behaviour change interventions. Implement Sci. 2011:6(1):42. https://doi.org/10.1186/1748-5908-6-42.

14. Leon $\mathrm{N}$, et al. Intervention development of a brief messaging intervention for a randomised controlled trial to improve diabetes treatment adherence in sub-Saharan Africa. BMC Public Health. 2021:1-14. https://doi.org/10.11 86/s12889-020-10089-6.

15. Peterson AM, Nau DP, Cramer JA, Benner J, Gwadry-Sridhar F, Nichol M. A checklist for medication compliance and persistence studies using retrospective databases. Value Health. 2007;10(1):3-12. https://doi.org/1 0.1111/j.1524-4733.2006.00139.x.

16. Stevens R, Kothari V, Adler A, Stratton I, Holman R. The UKPDS risk engine: a model for the risk of coronary heart disease in type II diabetes (UKPDS 56). Clin Sci. 2001;101(6):671-9. https://doi.org/10.1042/CS20000335.

17. EuroQol Group. EuroQol--a new facility for the measurement of healthrelated quality of life. Health Policy. 1990;16:199-208.

18. Wouters E, Heunis C, van Rensburg D, Meulemans H. Patient satisfaction with antiretroviral services at primary health-care facilities in the Free State, South Africa - a two-year study using four waves of cross-sectional data. BMC Health Serv Res. 2008:8(1):210. https://doi.org/10.1186/1472-6963-8-210.

19. Bhargava A, Booysen FL. Healthcare infrastructure and emotional support are predictors of CD4 cell counts and quality of life indices of patients on antiretroviral treatment in Free State Province, South Africa. CAIC. 2010;22:1-9.

20. Horne R, Weinman J. Patients' beliefs about prescribed medicines and their role in adherence to treatment in chronic physical illness. J Psychosom Res. 1999:47(6):555-67. https://doi.org/10.1016/50022-3999(99)00057-4.

21. Farmer A. Mobile messaging support versus usual care for people with type 2 diabetes on glycemic control: protocol for a multicenter randomized controlled trial. JMIR Res Protoc. 2019;8(6):e12377. https://doi.org/10.21 96/12377.

22. Schulz KF, Altman DG, Moher D, Trials CG. CONSORT 2010 statement: updated guidelines for reporting parallel group randomised trials. Lancet. 2010. https://doi.org/10.1016/S0140

23. Haider R, Sudini L, Chow CK, Cheung NW. Mobile phone text messaging in improving glycaemic control for patients with type 2 diabetes mellitus: a systematic review and meta-analysis. Diabetes Res Clin Pract. 2019;150:2737. https://doi.org/10.1016/.jiabres.2019.02.022.

24. Laura Martinengo PSJC. Mobile messaging with patients; 2020. p. 1-7. https://doi.org/10.1136/bmi.m884.

25. Ricci-Cabello I, Bobrow K, Islam SMS, Chow CK, Maddison R, Whittaker R, et al. Examining development processes for text messaging interventions to prevent cardiovascular disease: systematic literature review. JMIR mHealth uHealth. 2019;7(3):e12191-13. https://doi.org/10.2196/12191.

26. Dobson $\mathrm{R}$, et al. Effectiveness of text message based, diabetes self management support programme (SMS4BG): two arm, parallel randomised controlled trial. BMJ. 2018:k1959-10. https://doi.org/10.1136/bmj.k1959.

27. Bobrow K, Farmer AJ, Springer D, Shanyinde M, Yu LM, Brennan T, et al. Mobile phone text messages to support treatment adherence in adults with high blood pressure (SMS-text adherence support [StAR]): a single-blind, randomized trial. Circulation. 2016;133(6):592-600. https://doi.org/10.1161/ CIRCULATIONAHA.115.017530.

28. Michie S, Johnston M, Francis J, Hardeman W, Eccles M. From theory to intervention: mapping theoretically derived behavioural determinants to behaviour change techniques. Appl Psychol. 2008;57(4):660-80.

\section{Publisher's Note}

Springer Nature remains neutral with regard to jurisdictional claims in published maps and institutional affiliations.

\section{Ready to submit your research? Choose BMC and benefit from:}

- fast, convenient online submission

- thorough peer review by experienced researchers in your field

- rapid publication on acceptance

- support for research data, including large and complex data types

- gold Open Access which fosters wider collaboration and increased citations

- maximum visibility for your research: over $100 \mathrm{M}$ website views per year

At BMC, research is always in progress.

Learn more biomedcentral.com/submissions 